\title{
The intermediate alternative effect: Considering a small tradeoff increases subsequent willingness to make large tradeoffs
}

\author{
Gabriele Paolacci ${ }^{\mathrm{a}, *}$, Katherine A. Burson ${ }^{\mathrm{b}}$, Scott I. Rick ${ }^{\mathrm{b}}$ \\ a Department of Management, Ca' Foscari University of Venice, 873 Cannaregio, 30121 Venice, Italy \\ ${ }^{\mathrm{b}}$ Department of Marketing, Ross School of Business, University of Michigan, 701 Tappan Street, Ann Arbor, MI 48109, USA
}

Received 1 November 2010; revised 14 March 2011; accepted 18 April 2011

Available online 1 June 2011

\begin{abstract}
Prior research has consistently demonstrated that people are reluctant to trade a good they own for an alternative good, particularly when the alternative (or "target") represents a substantial departure from the "endowment". We demonstrate that the endowment effect can be reduced by first making participants consider trading their endowment for an intermediate alternative (which shares some characteristics of the endowment and some characteristics of the target). We find that this "intermediate alternative effect" operates primarily by shifting one's reference point in the direction of the target alternative. Even when the intermediate alternative is not adopted, the extent to which one's endowment is treated as a reference point is weakened, which can also facilitate subsequent trading.
\end{abstract}

(C) 2011 Society for Consumer Psychology. Published by Elsevier Inc. All rights reserved.

Keywords: Endowment effect; Loss aversion; Decision making; Reference point; Prospect theory

Countless studies have demonstrated that ownership of a good makes people reluctant to trade it for an alternative (e.g., Kahneman, Knetsch, \& Thaler 1990). This "endowment effect" (Thaler 1980) implies that consumers may make suboptimally conservative choices, such as keeping their current allotment (e.g., an inexpensive drug that has some side effects) although they might prefer an alternative (e.g., a more expensive drug that has no side effects) when asked to choose between the two. Endowment effects are most often interpreted as a manifestation of reference-dependent preferences that exhibit loss aversionthe tendency for losses to have greater hedonic impact than comparable gains (e.g., Thaler 1980; Tversky \& Kahneman 1981, 1986). Loss aversion contributes to the widespread (and often costly) influence of defaults on decision-making (e.g., Johnson \& Goldstein 2003; Thaler \& Sunstein 2008).

\footnotetext{
* Corresponding author. Fax: +39 0412348701.

E-mail addresses: paolacci@unive.it (G. Paolacci), kburson@umich.edu (K.A. Burson), srick@umich.edu (S.I. Rick).
}

We demonstrate a straightforward method to reduce the common reluctance to trade an endowment for a "target alternative." We propose that the process of deciding whether or not to trade the endowment for an "intermediate alternative" (an option that possesses characteristics of both the endowment and the target alternative) subsequently reduces the extent to which trading for the target alternative is viewed as a loss, which in turn stimulates trading. We propose that this "intermediate alternative effect" operates primarily by shifting one's reference point in the direction of the target alternative (among people who actually adopt the intermediate). However, even when the intermediate alternative is not adopted, the extent to which one's endowment is treated as a reference point is weakened, which may also facilitate subsequent trading.

Theoretically, we build upon work on reference dependence and similarity. We anticipate that adopting the intermediate alternative will shift one's reference point toward the target alternative, which should make the prospect of trading for the target alternative feel like less of a loss. This intuition stems from research suggesting that the similarity of alternatives may moderate the endowment effect (e.g., Chapman 1998; Ortona \& 
Scacciati 1992; Tversky \& Kahneman 1991; van Dijk \& van Knippenberg 1998). In all such studies, the number of trades from an endowment to a target alternative increased with the similarity or substitutability between the endowment and the target. For example, Samuelson and Zeckhauser (1988) found that Harvard employees were more likely to choose a slightly modified medical plan than to choose a new plan as a substitute for their current plan. Reference dependence and loss aversion together explain this moderation. When the consumer examines an alternative to her endowment, its relative attractiveness depends on the magnitude of the entailed tradeoff such that small tradeoffs are usually preferred to large tradeoffs. More formally, in prospect theory terms (Kahneman \& Tversky 1979), it is generally the case that if $x<y$, then $\mathrm{v}(x)+\mathrm{v}(-x)>\mathrm{v}(y)+\mathrm{v}(-y)$. Thus, people who refuse to "leap" from their endowment to a distant target alternative might instead "walk" to it. Other work also supports the notion that people will be willing to make what they perceive as small tradeoffs. For example, there is some evidence that small gains actually loom larger than small losses (e.g., Harinck, Van Dijk, Van Beest, \& Mersmann 2007).

Intermediate alternatives may help to facilitate subsequent trading even when they are rejected. Knetsch and Wong (2009) recently argued that endowment effects are largely dependent on the extent to which the endowment conveys the reference state. In particular, they showed that the consideration of counterfactual endowments may undermine the strength of the individual's reference point (i.e., the extent to which one's endowment serves as the salient reference point against which potential trades are evaluated). This is consistent with recent work that has demonstrated that individuals with extensive trading experience, such as professional sports card dealers (List 2003) and real estate investors (Genesove \& Mayer 2001), are less reluctant to part with their endowments than are those with less experience. Similarly, putting participants in a less emotional trading mindset has been shown to reduce loss aversion (Sokol-Hessner et al. 2009). Reconciling such evidence with a reference point account of the endowment effect (cf. Knetsch \& Wong 2009), we maintain that facing an opportunity to trade one's endowment for an intermediate alternative can weaken the extent to which the endowment is treated as the reference point. This, in turn, should make the prospect of trading away one's endowment feel like less of a loss. In essence, rejecting the intermediate may subsequently make the decision whether to exchange one's endowment for the target alternative feel more like a choice between receiving the endowment and receiving the target alternative (i.e., help to turn "owners" into "choosers").

Of course, even if the reference point is weakened, it is unlikely that intermediate-rejectors will completely re-set their reference point (i.e., behave purely as choosers who have no endowment), since they still physically retain their endowment. However, intermediate-adopters, whose reference point has shifted toward the target, must endure only a small loss to obtain it. Moreover, if the loss is indeed perceived as small, the prospect of gaining the target might be weighted more heavily than the prospect of losing the intermediate (cf. Harinck et al. 2007), further increasing the likelihood of trading. Accordingly, we anticipate that the overall intermediate alternative effect will be driven primarily by intermediate-adopters.

Taken together, the reasoning above leads to the following hypotheses:

H1. People who consider trading their endowment for an intermediate alternative will subsequently be more likely to trade for a distant (target) alternative than people who do not initially consider trading their endowment for an intermediate alternative.

H1a. Intermediate-adopters will be more likely to trade for the target than intermediate-rejectors.

We begin by examining the intermediate alternative effect and its underlying reference point dynamics using the basic paradigm illustrated in Fig. 1. Imagine a consumer who is reluctant to trade her endowment for a distant target alternative even though she would prefer such an alternative in a simple binary choice. We propose that this endowment effect can be overcome by employing a two-step trading process from the endowment to the target alternative (see Intermediate panel of Fig. 1). Specifically, consumers who would refuse to trade their endowment for the target alternative (path 1 in the Baseline panel of Fig. 1) may ultimately do so by first considering trades for intermediate alternatives (path 1-then-2' or path 2 in the Intermediate panel). We argue that considering whether or not to trade one's endowment for an intermediate alternative subsequently reduces the extent to which trading for the target alternative is viewed as a loss, either by weakening the reference

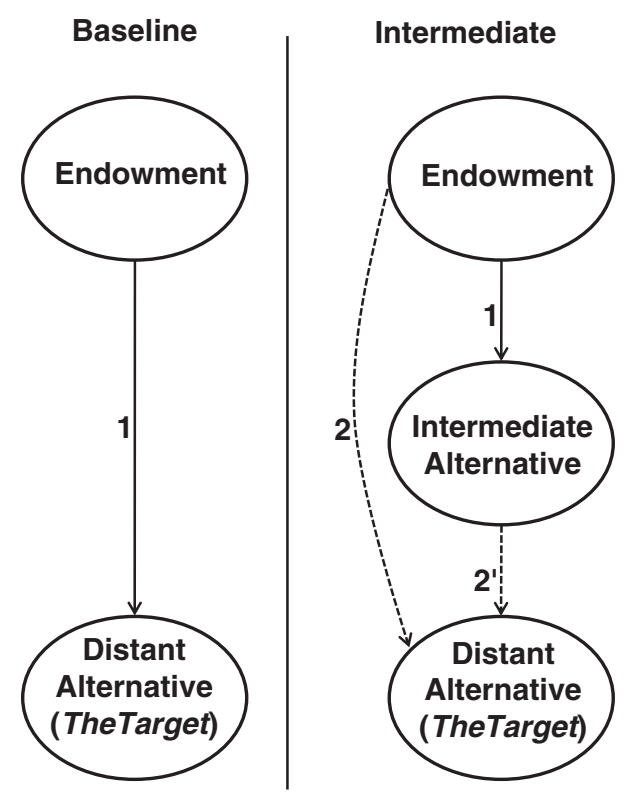

Fig. 1. The basic experimental paradigm. Note that each arrow represents a single choice. There is one choice in the Baseline condition and two choices in the Intermediate condition. The second choice in the Intermediate condition depends on whether the intermediate alternative is adopted. If the intermediate alternative is rejected, the second choice is between the endowment and the target (link 2). If the intermediate is adopted, the second choice is between the intermediate alternative and the target (link $2^{\prime}$ ). 
point conveyed by the endowment (if the intermediate is rejected) or by shifting it toward the target alternative (if the intermediate is adopted). This will, in turn, increase the likelihood of trading to the target alternative.

\section{Study 1: Trading theater seats}

In Study 1 we examine whether there is an intermediate alternative effect by comparing trading rates (the proportion of people who ultimately adopt the target alternative) between a Baseline condition and an Intermediate condition (see Fig. 1). In a hypothetical concert scenario, participants were endowed with seats in a theater and decided whether to trade for alternative seats characterized by tradeoffs (proximity to friends and proximity to the stage). Regardless of the features of the original endowment, we predicted that participants who had previously encountered an opportunity to trade the endowment for an intermediate alternative would be more likely to trade to the distant target alternative than those who had not encountered the intermediate alternative.

\section{Procedure}

One hundred twenty-two adults (mean age $=33.4,59 \%$ female) participated via Amazon Mechanical Turk, an online service validated as a survey website (Horton et al. in press; Paolacci, Chandler, \& Ipeirotis 2010). Participants were asked to imagine that they and three of their friends would soon attend a concert of their favorite artist. Each participant was then assigned the hypothetical task of buying all four tickets based on two criteria: 1) the four seats should be as close as possible to the stage in order to have the best possible view; and 2) the four seats should be as close as possible to each other in order to enjoy the concert together. The cover story reported that at the time of purchase there was only one set of tickets available, and we counterbalanced across participants which endowment they received: either four seats that were superior on proximity to each other (Fig. 2, Panel A, henceforth referred to as Fig. 2A), or four seats that were superior on proximity to the stage (Fig. 2, Panel B, henceforth referred to as Fig. 2B). (Complete instructions and stimuli are available from the authors upon request.)

We randomly assigned participants to either a Baseline condition or an Intermediate condition. Participants in the Baseline condition were simply provided with the opportunity to keep their endowed set of seats or trade them for a set of seats that ostensibly just became available, namely the target alternative (those who were endowed with the seats in Fig. 2A were offered the seats in Fig. 2B, and vice versa). Participants in the Intermediate condition were initially given the opportunity to trade their endowed set of seats for an intermediate set of seats (Fig. 2, Panel C, henceforth referred to as Fig. 2C). The seats in Fig. 2C are intermediate on both the "proximity to stage" dimension (closer to the stage than the Fig. 2A seats, but farther than the Fig. 2B seats) and the "proximity to friends" dimension (less clustered than the Fig. 2A seats, but more clustered than the Fig. 2B seats). All Intermediate participants (whether or not they
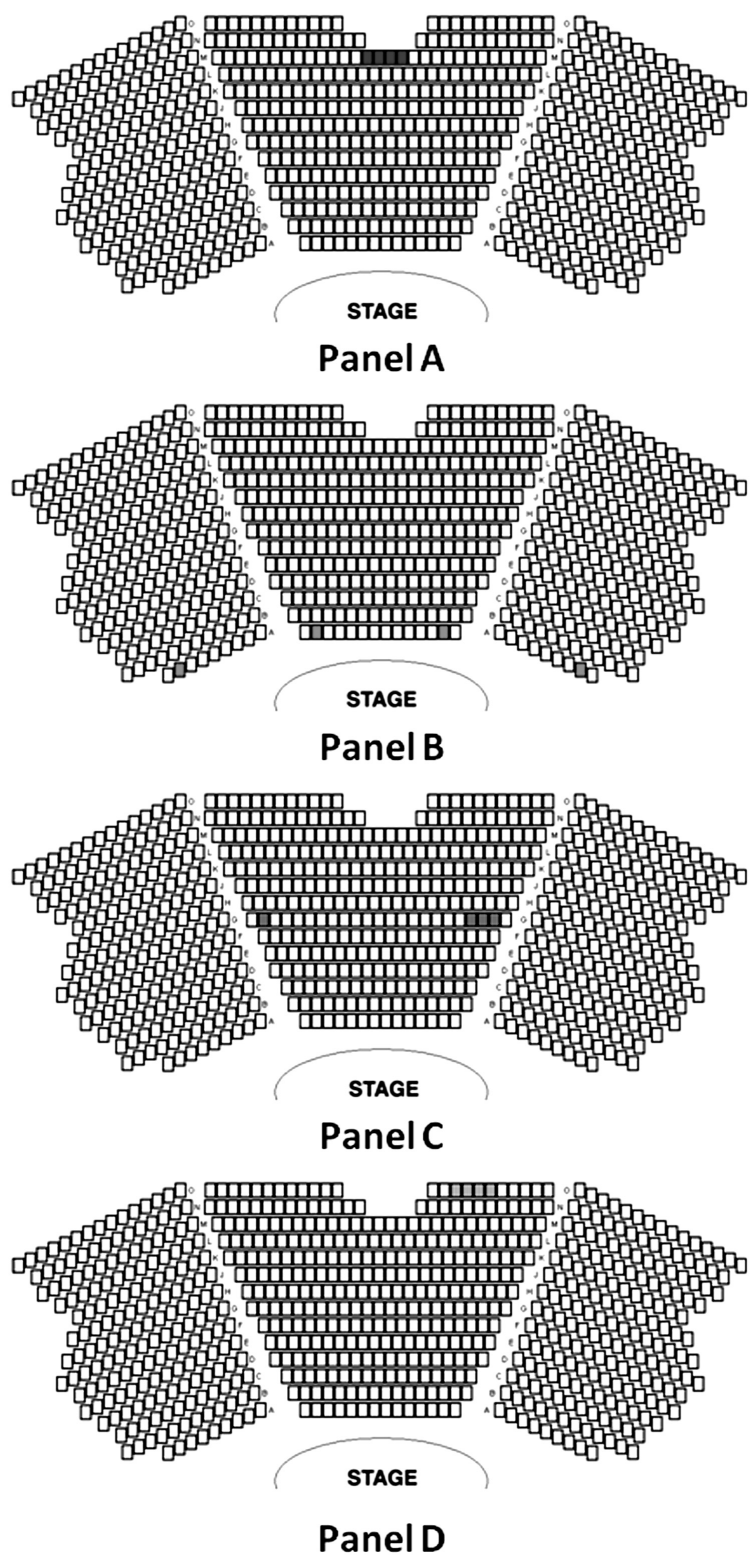

Fig. 2. Study 1 and Study 3 theater maps.

decided to trade for the intermediate alternative) were then asked whether they wanted to trade their current seats for the target alternative. ${ }^{1}$

Comparing trading rates in the Baseline and the Intermediate condition reveals whether or not consideration of an intermediate alternative attenuates the endowment effect. Regardless of whether participants naturally prioritize proximity to stage or proximity to friends, because we counterbalance whether participants are endowed with one option or the other, the classical economic prediction is that half of the participants in the Baseline condition should trade away their endowed set of

\footnotetext{
${ }^{1}$ To make the task as clear as possible, participants were reminded of the position of their current seats throughout the experiment. In particular, while making their choices, participants could observe each alternative in a distinct map similar to the panels in Fig. 2.
} 
tickets. Trading rates below $50 \%$ are indicative of an endowment effect. ${ }^{2}$

\section{Results and discussion}

Consistent with prior research, we observed an endowment effect in the Baseline condition. Only $29.6 \%$ of participants in the Baseline condition chose to trade away their endowed set of seats for the target alternative seats, a proportion significantly lower than the normative benchmark of $50 \%\left(\chi^{2}(1)=8.96\right.$, $p<.01)$. However, consistent with $\mathrm{H} 1$, participants who were presented with an intermediate alternative were significantly more likely to trade. Among participants in the Intermediate condition, $47.1 \%$ ultimately traded their endowed set of seats for the target alternative seats. This trading rate is significantly higher than the $29.6 \%$ trading rate in the Baseline condition $\left(\chi^{2}(1)=3.83, p=.05\right)$. Moreover, $47.1 \%$ is not significantly different from the $50 \%$ normative benchmark $\left(\chi^{2}(1)=.24\right.$, $p=.63)$, meaning that the endowment effect is statistically nonexistent in the Intermediate condition. In addition, in the Intermediate condition, participants who adopted the intermediate alternative were more likely to trade for the target than people who rejected the intermediate $\left(66.7 \%\right.$ vs. $41.5 \%, \chi^{2}(1)=$ $2.97, p=.08)$. This provides support for H1a and is consistent with our proposition that adopting an intermediate alternative does indeed shift the reference point toward the target, whereas rejecting an intermediate alternative can only weaken it.

\section{Study 2: Trading chocolate}

The difference in subsequent trading between intermediateadopters and intermediate-rejectors observed in Study 1 suggests that reference point shifting is the critical component of the intermediate alternative effect. However, it must be acknowledged that two things differ between intermediateadopters and intermediate-rejectors: Unlike intermediaterejectors, (i) intermediate-adopters have parted with the endowment and (ii) have obtained the intermediate alternative. The current results cannot pinpoint whether the difference between intermediate-adopters and intermediaterejectors is primarily driven by (i) parting with the endowment or (ii) obtaining the intermediate. If the trading-rate difference between intermediate-adopters and intermediate-rejectors is primarily driven by parting with the endowment, then reference point shifting is not the essential component of the intermediate alternative effect. Instead, that might suggest that the effect is driven primarily by reference point weakening (and that parting with the endowment by accepting the

\footnotetext{
2 To explain this prediction formally, imagine that a share $p$ of all participants prefer the close-to-stage seats to the clustered ones. Then, assuming no reference dependence, in the condition where participants are endowed with close-to-stage seats, a share $1-p$ should exchange the close-to-stage seats for the clustered seats; in the condition where participants are endowed with clustered seats, a share $p$ should exchange clustered seats for close-to-stage seats. If the number of participants is the same across conditions, this would produce an average trading rate of $(p+1-p) / 2=1 / 2$. Therefore, a trading rate lower than $50 \%$ is evidence of an endowment effect.
}

intermediate simply does a better job of reference point weakening than rejecting the intermediate).

Study 2 examines the relative contributions of parting with the endowment and obtaining the intermediate by introducing a Parallel condition (see Fig. 3). Specifically, we examine the ability of a "parallel alternative" (which differs only superficially from the endowment) to increase subsequent trading. Notice that the act of adopting the parallel alternative requires parting with the endowment, but it cannot shift the reference point toward the target. If the intermediate alternative effect is primarily driven by the reference point shifting toward the target when that intermediate is adopted, the ultimate trading rates should not increase when a parallel alternative is considered, since it cannot shift one's reference point toward the target, even if adopted. Indeed, if reference point shifting is the primary component of the intermediate alternative effect, the following predictions can be made:

H2. Relative to the Baseline condition, trading rates will not increase when a parallel alternative is considered instead of an intermediate alternative.

H2a. People who initially adopt an intermediate alternative will be more likely to trade for the target alternative than people who initially adopt a parallel alternative.

In addition to testing these hypotheses, Study 2 examines whether the intermediate alternative effect persists when participants must make real choices between goods. Specifically, participants were confronted with real choices between bags of customized milk chocolate M\&M's. Participants traded

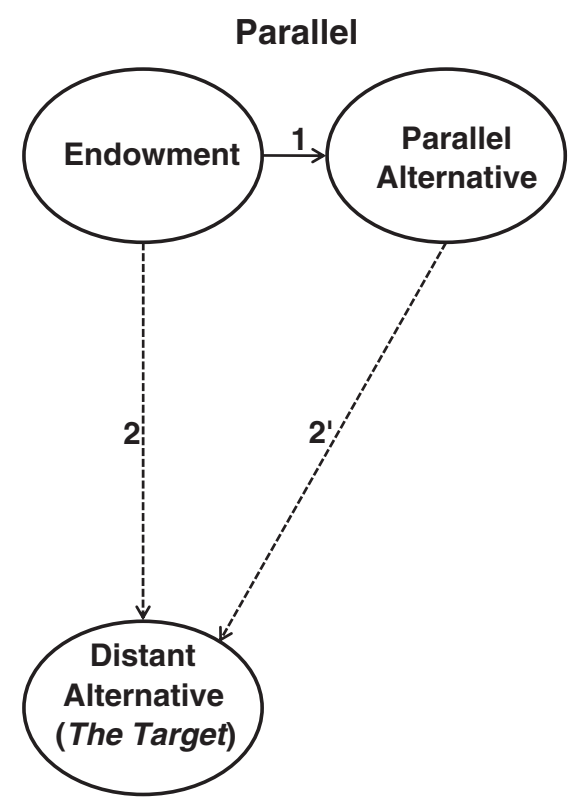

Fig. 3. The Parallel Alternative condition. There are two choices in the Parallel condition. The second choice in the Parallel condition depends on whether the parallel alternative is adopted. If the parallel alternative is rejected, the second choice is between the endowment and the target (link 2). If the parallel alternative is adopted, the second choice is between the parallel alternative and the target (link $2^{\prime}$ ). 
between bags of M\&M's that were characterized by tradeoffs (number of bags and aesthetic appeal).

\section{Procedure}

One hundred and twelve female participants at University of Michigan completed this study in exchange for a $\$ 10$ participation fee. They were randomly assigned to one condition of a 2 (endowment: university M\&M's or spider M\&M's) $\times 3$ (path to target: baseline, intermediate, or parallel alternative) between-participants design. Participants were initially endowed with either two small bags of M\&M's customized with University of Michigan's logo or with four small bags of M\&M's customized with an unpleasant picture of a spider (see Fig. 4). These two options were thus characterized by a relatively large tradeoff in terms of the quantity of chocolate and the aesthetic appeal of the candies (a pretest indicated that females found university M\&M's more attractive than spider M\&M's). To reinforce participants' feeling of ownership for the M\&M's they initially received, we first asked them to estimate the weight of a single bag (all bags weighed $1.15 \mathrm{oz}$.), and paid them $\$ 1$ at the end of the study if their estimate fell within $\pm 0.25 \mathrm{oz}$ of the actual weight.

Participants in the Baseline condition saw no intermediate alternative and were simply asked if they wanted to trade their two bags of university M\&M's for four bags of spider M\&M's, or vice versa. Participants in the Intermediate condition were first given the opportunity to trade their endowment for an

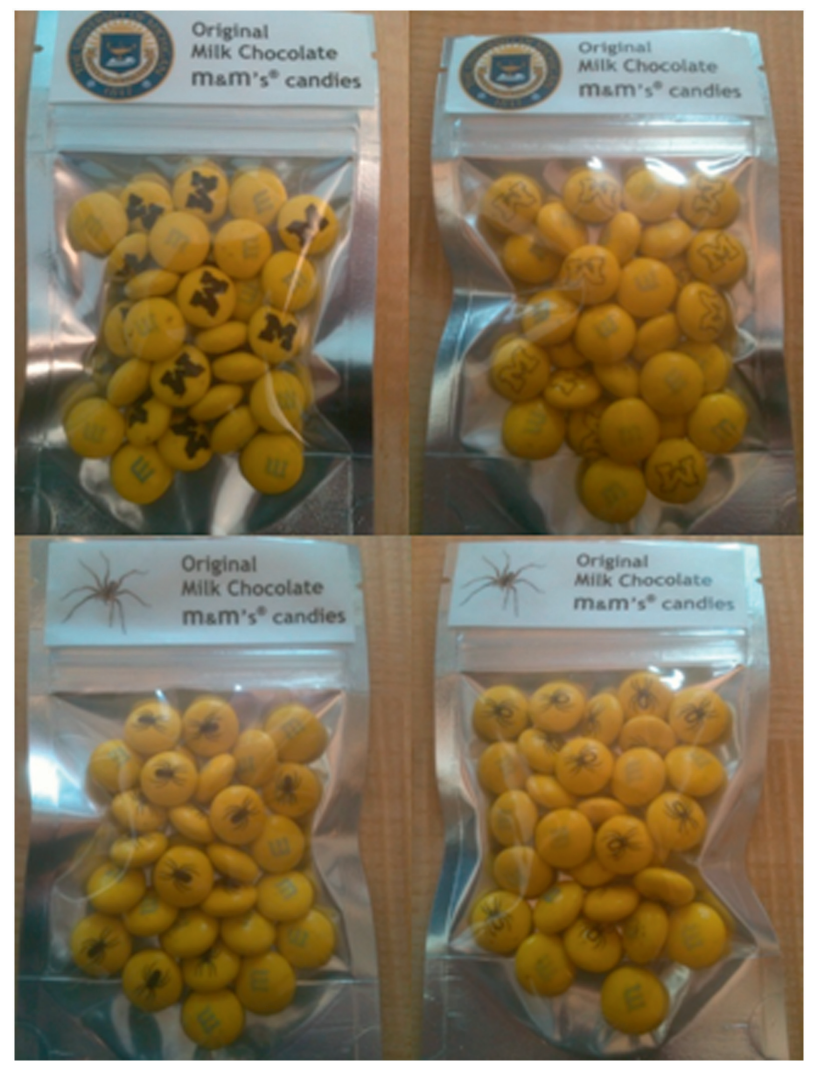

Fig. 4. Sample stimuli from Study 2, Clockwise, from upper left: Solid university M\&M's, outlined university M\&M's, outlined spider M\&M's, solid spider M\&M's. intermediate alternative composed of one bag of university M\&M's and two bags of spider M\&M's. After this choice, participants were offered the opportunity to trade their current allotment for the target alternative (two bags of university M\&M's if they began with four bags of spider M\&M's, or four bags of spider M\&M's if they began with two bags of university M\&M's). Participants in the Parallel condition were not initially offered an intermediate, but rather a slightly modified version of their initial endowment. These parallel alternatives were identical to the initial endowment except that the image was slightly different. For instance, a participant endowed with four bags of solid brown spider M\&M's was given the opportunity to trade for four bags of brown-outlined spider M\&M's (Fig. 4). Given its trivial difference from the endowment, there is little reason to suspect that adopting the parallel alternative would shift the reference point toward the target. If intermediateadopters trade more for the target than intermediate-rejectors because their reference point is shifted, intermediate-adopters should also be more likely to trade for the target than paralleladopters.

\section{Results and discussion}

Consistent with prior research, we observe an endowment effect in the Baseline condition. Participants in the Baseline condition traded their endowed set of M\&M's $25.0 \%$ of the time, indicative of a significant endowment effect $\left(\chi^{2}(1)=9.00\right.$, $p<.01)$. By contrast, $47.2 \%$ of participants in the Intermediate condition traded their M\&M's for the target alternative. This trading rate is significantly higher than the trading rate in the Baseline condition $\left(\chi^{2}(1)=3.85, p<.05\right)$, illustrating once again that considering an intermediate alternative substantially increases trading and eliminates the endowment effect (47.2\% vs. $\left.50 \%, \chi^{2}(1)=.06, p=.81\right)$.

We next examined the pattern of trading for the Parallel condition. There, $35.0 \%$ of participants traded from the endowment to the target alternative. Although the difference in trading rates between the Parallel condition and the Baseline condition (35.0\% vs. $25.0 \%)$ is directionally consistent with the idea that considering trading away the endowment weakens the reference point, this difference was not significant $\left(\chi^{2}(1)=0.90\right.$, $p=.34)$. Indeed, consistent with $\mathrm{H} 2$, participants in the Parallel condition also exhibited an endowment effect $(35.0 \%$ vs. $\left.50.0 \%, \chi^{2}(1)=3.60, p=.06\right)$.

To provide a focused test of $\mathrm{H} 2 \mathrm{a}$, we compare the behavior of adopters and rejectors in the Intermediate and Parallel conditions. Fig. 5 summarizes the results. Consistent with Study 1 , intermediate-adopters were significantly more likely to trade for the target than intermediate-rejectors $(63.2 \%$ vs. $29.4 \%$, $\left.\chi^{2}(1)=4.10, p<.05\right)$. By contrast, parallel-adopters were no more likely to trade for the target than parallel-rejectors $(33.3 \%$ vs. $\left.36.4 \%, \chi^{2}(1)=0.04, p=.84\right)$. Most importantly, whereas intermediate-rejectors and parallel-rejectors did not significantly differ in the extent to which they ultimately traded for the target $\left(29.4 \%\right.$ vs. $\left.36.4 \%, \chi^{2}(1)=0.21, p=.65\right)$, intermediateadopters were nearly twice as likely as parallel-adopters to subsequently trade for the target $\left(63.2 \%\right.$ vs. $33.3 \%, \chi^{2}(1)=$ 


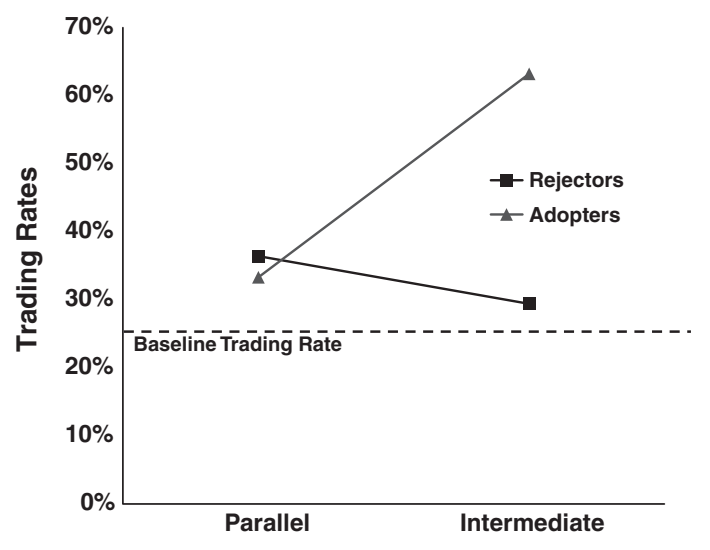

Fig. 5. Trading rates for the target by condition in Study 2 .

$3.29, p=.07)$. Because adopting the parallel alternative can only weaken one's reference point, but not shift it in the direction of the target, this large difference suggests that reference point shifting is the critical component of the intermediate alternative effect.

Given the demonstrated importance of reference point shifting via intermediate-adoption, it is worth considering whether, and to what extent, reference point weakening via intermediate-rejection actually contributes to the intermediate alternative effect. Though we have shown that reference point shifting is critical, it is difficult to precisely measure the relative contributions of shifting vs. weakening. It is tempting to compare trading rates for the target among intermediate-rejectors and Baseline participants. Across studies, intermediate-rejectors were about $4-12 \%$ more likely to trade for the target than Baseline participants (41.5\% vs. $29.6 \%$ in Study $1 ; 29.4 \%$ vs. $25.0 \%$ in Study 2). However, this is essentially an apples-tooranges comparison because we know that all intermediaterejectors prefer the endowment to the intermediate, but some Baseline participants would undoubtedly have preferred the intermediate to the endowment. Arguably, then, this 4-12\% estimate understates the extent to which reference point weakening contributes to the overall effect. (The appropriate, but impossible comparison would be between intermediaterejectors and Baseline participants who would have rejected the intermediate.)

The Parallel condition is another relevant source of data. Since the parallel alternative differs only slightly from the endowment, accepting or rejecting it is unlikely to do anything other than weaken one's reference point. (Indeed, the difference in trading rates for the target between parallel-adopters and parallel-rejectors does not even approach significance; $p=.84$.) The overall $10 \%$ difference in trading rates for the target between Parallel participants and Baseline participants (35\% vs. $25 \%$ ) provides another estimate of the benefits of reference point weakening. Thus, the results suggest that weakening plays a small, but non-negligible role in the overall effect.

Study 2 served several purposes. Using real products, we replicated the intermediate alternative effect and, as in Study 1, found that it was primarily driven by intermediate-adopters rather than intermediate-rejectors. In addition, by introducing a
Parallel condition, we were able to determine whether the intermediate alternative effect is primarily driven by reference point shifting or by reference point weakening. The large trading difference between intermediate-adopters and paralleladopters suggests that effect is primarily driven by reference point shifting.

One limitation of Studies 1 and 2, however, is that they measure only participants' behavior. The trading data is consistent with our proposed process of reference point weakening and shifting, but does not directly measure those reference points. Therefore, in Study 3 we use a more sensitive measure of participants' reference points: We measure continuous satisfaction ratings that likely correspond more closely to reference points than binary trading decisions.

\section{Study 3: Judging theater seats}

In Study 3 we used a concert scenario similar to Study 1 to provide a more sensitive test of the precise influence of intermediate alternatives on reference points. We manipulated whether or not participants were endowed with a set of seats, and among people who were endowed with seats, we manipulated whether or not they were offered an alternative that represented a small tradeoff (for a total of three betweenparticipants conditions). We then asked all participants how satisfied they would be with a set of seats that was dominated by the endowment. Degree of satisfaction with the dominated alternative arguably reflects the perceived distance between a participant's current state and the dominated alternative (such that a larger distance between the two would lead to lower satisfaction with the dominated alternative). If reference points are shifted by adopting the intermediate alternative, dissatisfaction with a dominated option should be greatest among intermediate-adopters. If rejecting an intermediate weakens one's reference point, the satisfaction ratings of intermediaterejectors should be similar to the satisfaction ratings of nonendowed participants.

\section{Procedure}

Two hundred adults (mean age $=35.6,61 \%$ female) recruited on Amazon Mechanical Turk were randomly assigned to one of the three conditions: Baseline, Intermediate, and No Endowment. In the Baseline condition, participants were endowed with a set of side-by-side seats that were moderately far from the stage (Fig. 2A). They were then asked to imagine that they had to move to a set of dominated side-by-side seats in the back row (even further back than the endowed set; Fig. 2, Panel D), and were asked how satisfied they would be with those seats on a $1-$ 7 scale ( 1 = extremely unsatisfied, 7 =extremely satisfied). In the Intermediate condition, participants were first asked whether they wanted to move to a set of less clustered seats in the middle of the theater (the intermediate alternative in Study 1; Fig. 2C), and were then asked how satisfied they would be with the dominated seats. In the No Endowment condition, participants were simply asked how satisfied they would be with the dominated seats. 


\section{Results and discussion}

Consistent with reference dependence, participants in the Baseline condition were significantly less satisfied with the dominated seats than participants in the No Endowment condition $(3.85$ vs. 4.90, $t(123)=2.11, p<.05)$. However, there was no significant difference between participants who considered and rejected the intermediate alternative and participants in the No Endowment condition (4.37 vs. 4.90, $t(120)=1.13, p=.26)$. These patterns suggest that, as predicted, rejecting the intermediate weakened the reference point (though not completely re-setting it to a state like that before they were endowed). In addition, participants who considered and adopted the intermediate alternative were less satisfied with the dominated seats than Baseline participants $(2.83$ vs. $3.85, t(78)=1.87, p=.07)$, suggesting their reference point had shifted as a result of the trade.

These results fully support our weakening and shifting reference point account of the intermediate alternative effect. Rejecting an intermediate alternative to one's endowment weakens the reference state instilled by the endowment, and adopting such an alternative shifts the reference point. Taken together with the results from Studies 1 and 2, the results strongly suggest that intermediate alternatives reduce the endowment effect by weakening reference points (if rejected) and shifting reference points (if adopted).

\section{General discussion}

Too often, consumers are stuck with choices they inherited from the past, rejecting favorable alternatives to their endowments because the losses they perceive are too difficult to ignore (e.g., Okada 2001). We demonstrate that reluctance to trade can be reduced by first providing the consumer with an opportunity to trade the endowment for a smaller tradeoff option. Through consideration of that intermediate alternative, participants abandoned their endowments and adopted alternatives they likely would have rejected if forced to trade for them directly.

This paper joins a growing body of literature that identifies context-based boundaries of the endowment effect (e.g., Lerner, Small, \& Loewenstein 2004) and contributes to our understanding of the endowment effect by showing that an incremental presentation of alternatives attenuates it: In our studies, participants who considered owning an intermediate alternative before considering the target alternative showed no endowment effect. We maintain that this pattern results from a reference point mechanism that makes the trade for the target alternative feel like less of a loss: Rejecting the intermediate alternative weakens the reference state conveyed by the endowment, and adopting the intermediate shifts the reference point from the endowment toward the target.

Our work also joins a growing body of research that attempts to shed light on how reference points develop and change over time (e.g., Heffetz \& List 2011; Köszegi \& Rabin 2006). For example, the results of Study 3 suggest that reference points are not strictly defined by ownership (cf. Ericson \& Fuster in press; Peck \& Shu 2009).
Some readers may see parallels between the current research and findings on context-dependent choices (Huber, Payne, \& Puto 1982). The present findings do not contradict existing research on the compromise effect (Simonson 1989): Whereas the compromise effect posits that an intermediate alternative benefits from the presence of an extreme alternative (in terms of choice share), we demonstrate that introducing an intermediate before introducing an extreme alternative can subsequently benefit the extreme alternative. Similarly, our findings are not a replication of the attraction effect: Whereas the attraction effect illustrates how the addition of a dominated option can pull choice share to an extreme option, we always use a nondominated intermediate option.

Readers familiar with the classic foot-in-the-door (FITD) phenomenon, whereby willingness to comply with a large request is increased when preceded by a small request, may also see overlap between this effect and the intermediate alternative effect. However, a closer look reveals several distinctions. Note that the intermediate alternative effect is a way to increase willingness to make tradeoffs between losses and gains, whereas FITD is a way to increase willingness to accept losses. Specifically, while we present participants with the opportunity to trade something desirable for something they may or may not find more desirable, FITD researchers attempt to coerce participants into behavior that they find unpleasant, such as allowing strangers into their home (Freedman \& Fraser 1966).

In addition, FITD researchers do not distinguish between people who comply and do not comply with the initial request (adopters and rejectors, in our language). When it is reported, the proportion of participants who comply with the first request is typically very high (e.g., 100\%, Burger \& Petty 1981, p. 497). Indeed, in a meta-analysis of FITD studies, Burger (1999, p. 305 ) found only one study in which the majority of participants did not comply with the initial request. High compliance with the initial request is not surprising given the lack of anonymity in FITD paradigms (requests are typically made in person or over the phone) and the fact that complying with the request does not require parting with a salient reference state (unlike owners deciding whether to trade away an endowment). Moreover, all participants, whether they comply with the small request or not, are lumped together and included in all analyses (e.g., Burger 1999; Freedman \& Fraser 1966). By contrast, we demonstrate that intermediate alternatives operate differently depending on whether or not they are adopted.

Finally, the FITD and intermediate alternative effects appear to be driven by different processes. Whereas FITD is typically attributed to self-perception, psychological reactance, a need to remain consistent, and several other factors (Burger 1999), those factors are not needed to explain the effectiveness of intermediate alternatives. Instead, intermediate alternatives appear to work by shifting or weakening reference points.

Future research should delve more deeply into the process by which adopting an intermediate alternative influences one's reference point. Our current data suggest that adopting the intermediate shifts the reference point. It is possible, however, that the reference point shift is actually a more nuanced process of initial weakening due to mere consideration of the trade and 
then shifting via adoption of the intermediate alternative. Comparing an Intermediate condition like those utilized in our studies to an Intermediate-to-Target condition, in which participants start with an intermediate alternative and decide whether to trade for the target, would be informative. If trading from the endowment to the intermediate both shifts and weakens one's reference point, subsequent trading to the target should be greater among intermediate-adopters in the Intermediate condition than among participants in the Intermediate-toTarget condition.

Our findings have practical relevance for marketers and policy makers. We suggest that when consumers are reluctant to undertake big changes, "smoothing" the transition process to the final state might help. There are a number of products and services that can be introduced and adopted (or not) in an incremental fashion, the most salient example being digital goods: Unless alternatives are very compelling, websites and software manufacturers should consider introducing new versions of their existing offers through incremental updates to minimize the net impact of perceived losses.

For policy makers, this proposal might be utilized as a "nudge" (Thaler \& Sunstein 2008) to overcome the problem of suboptimally conservative choices. Offering people small trades eases the path to a potentially beneficial but controversial alternative without forcing that trade. Consider, for instance, the problem of insufficient saving rates among American households. Since households are accustomed to a certain level of disposable income, they may be reluctant to save more money (even when they know they should) because they do not want to experience a "cut" in take-home pay (Thaler \& Benartzi 2004). Our results suggest that firms could implement successive contribution plans that only slightly increase employees' saving rates but eventually lead to more aggressive saving.

\section{Conclusion}

Although much is understood about loss aversion and the endowment effect, many open questions remain (cf. Johnson, Gachter, \& Herrmann 2006; McGraw, Larsen, Kahneman, \& Schkade 2010; Rick 2011). Our work contributes to answering those questions by explicating the role of weakened vs. shifted reference points in overcoming endowment effects. Practically, our work demonstrates a simple way to reduce the endowment effect. Consumers who consider trading their endowment for an intermediate alternative subsequently demonstrate no endowment effect when deciding whether to trade for a more distant alternative. Thus, to encourage tradeoffs, marketers and policy makers are advised to help people walk toward the desired outcome rather than trying to force them to leap.

\section{Acknowledgements}

The authors thank the Editor, two anonymous reviewers, David Faro, Yuval Rottenstreich, Robert Smith, and George Wu for helpful comments. The authors are also grateful to the
University of Michigan Ross School of Business for financial support.

\section{References}

Burger, J. M. (1999). The foot-in-the-door compliance procedure: A multipleprocess analysis and review. Personality and Social Psychology Review, 3 (4), 303-325.

Burger, J. M., \& Petty, R. E. (1981). The low-ball compliance technique: Task or person commitment? Journal of Personality and Social Psychology, 40 (3), 492-500.

Chapman, G. B. (1998). Similarity and reluctance to trade. Journal of Behavioral Decision Making, 11(1), 47-58.

Ericson, K. M., \& Fuster, A. (in press). Expectations as endowments: Evidence on reference-dependent preferences from exchange and valuation experiments. Quarterly Journal of Economics.

Freedman, J. L., \& Fraser, S. C. (1966). Compliance without pressure: The footin-the-door technique. Journal of Personality and Social Psychology, 4, 195-202.

Genesove, D., \& Mayer, C. (2001). Loss aversion and seller behavior: Evidence from the housing market. Quarterly Journal of Economics, 116(4), $1233-1260$.

Harinck, F., Van Dijk, E., Van Beest, I., \& Mersmann, P. (2007). When gains loom larger than losses. Psychological Science, 18(12), 1099-1105.

Heffetz, O., \& List, J. A. (2011). Is the endowment effect a reference effect? NBER Working Paper No. w16715.

Horton, J., Rand, D., \& Zeckhauser, R. (in press). The online laboratory: Conducting experiments in a real labor market. Experimental Economics.

Huber, J., Payne, J. W., \& Puto, C. (1982). Adding asymmetrically dominated alternatives: Violations of regularity and the similarity hypothesis. Journal of Consumer Research, 9(1), 90-98.

Johnson, E. J., Gachter, S., \& Herrmann, A. (2006). Exploring the nature of loss aversion. Working paper, Columbia University.

Johnson, E. J., \& Goldstein, D. (2003). Do defaults save lives? Science, 302 (5649), 1338-1339.

Kahneman, D., Knetsch, J. L., \& Thaler, R. H. (1990). Experimental tests of the endowment effect and the Coase theorem. Journal of Political Economy, 98 (6), 1325-1348.

Kahneman, D., \& Tversky, A. (1979). Prospect theory: An analysis of decision under risk. Econometrica, 47(2), 263-291.

Knetsch, J. L., \& Wong, W. (2009). The endowment effect and the reference state: Evidence and manipulations. Journal of Economic Behavior \& Organization, 71(2), 407-413.

Köszegi, B., \& Rabin, M. (2006). A model of reference-dependent preferences Quarterly Journal of Economics, 121(4), 1133-1165.

Lerner, J., Small, D., \& Loewenstein, G. (2004). Heart strings and purse strings: Effects of specific emotions on economic transactions. Psychological Science, 15(5), 337-341.

List, J. A. (2003). Does market experience eliminate market anomalies? Quarterly Journal of Economics, 118(1), 41-71.

McGraw, A. P., Larsen, J. T., Kahneman, D., \& Schkade, D. (2010). Comparing gains and losses. Psychological Science, 21(10), 1438-1445.

Okada, E. M. (2001). Trade-ins, mental accounting, and product replacement decisions. Journal of Consumer Research, 27(4), 433-446.

Ortona, G., \& Scacciati, F. (1992). New experiments on the endowment effect. Journal of Economic Psychology, 13(2), 277-296.

Paolacci, G., Chandler, J., \& Ipeirotis, P. G. (2010). Running experiments on Amazon Mechanical Turk. Judgment and Decision Making, 5(5), 411-419.

Peck, J., \& Shu, S. (2009). The effect of mere touch on perceived ownership. Journal of Consumer Research, 36(3), 434-447.

Rick, S. (2011). Losses, gains, and brains: Neuroeconomics can help to answer open questions about loss aversion. Journal of Consumer Psychology, 21(4), 451-461 (this issue).

Samuelson, W., \& Zeckhauser, R. (1988). Status quo bias in decision making Journal of Risk and Uncertainty, 1(1), 7-59.

Simonson, I. (1989). Choice based on reasons: The case of attraction and compromise effects. Journal of Consumer Research, 16(2), 158-174. 
Sokol-Hessner, P., Hsu, M., Curley, N. G., Delgado, M. R., Camerer, C. F., \& Phelps, E. A. (2009). Thinking like a trader selectively reduces individuals' loss aversion. Proceedings of the National Academy of Sciences, 106(13), 5035-5040.

Thaler, R. (1980). Toward a positive theory of consumer choice. Journal of Economic Behavior \& Organization, 1(1), 39-60.

Thaler, R. H., \& Benartzi, S. (2004). Save More Tomorrow ${ }^{\mathrm{TM}}$ : Using behavioral economics to increase employee saving. Journal of Political Economy, 112 (1), S164-S187.

Thaler, R. H., \& Sunstein, C. R. (2008). Nudge: improving decisions about health, wealth, and happiness. : Yale University Press.
Tversky, A., \& Kahneman, D. (1981). The framing of decisions and the psychology of choice. Science, 211(4481), 453-458.

Tversky, A., \& Kahneman, D. (1986). Rational choice and the framing of decisions. The Journal of Business, 59(4), S251-S278.

Tversky, A., \& Kahneman, D. (1991). Loss aversion in riskless choice: A reference-dependent model. Quarterly Journal of Economics, 106(4), $1039-1061$.

van Dijk, E., \& van Knippenberg, D. (1998). Trading wine: On the endowment effect, loss aversion, and the comparability of consumer goods. Journal of Economic Psychology, 19(4), 485-495. 